\title{
Family matters: infants, toddlers and preschoolers of parents affected by mental illness
}

\author{
Early interventions targeting adverse influences on young children and their parents can \\ improve children's outcomes
}

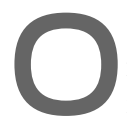
ne in five young people in Australia, including infants, toddlers and preschoolers, lives in a family with a parent with a mental illness. ${ }^{1}$ Families affected by mental illness are more likely than other families to experience poverty and social isolation, ${ }^{2}$ and are more likely to have children taken into care. ${ }^{3}$

A combination of factors influences the child's risk of psychopathology. These include psychosocial adversity, the child's developmental status and age, genetics, family relationships, the severity and chronicity of parental psychiatric disorder, comorbidity, and the involvement of other carers in the child's life. Not all children whose parents have mental health problems will experience difficulties themselves. ${ }^{4}$

Parental diagnosis itself does not confer risk, and many parents with severe depression, schizophrenia and other disorders are adequate caregivers. ${ }^{5}$ Rather, it is the severity and chronicity of psychopathology and the variation in parental personality, genetic characteristics, coping style and social circumstances that confer risk. Children's characteristics, such as temperament and sex, can also influence the parent-child relationship and parenting behaviour. $^{6}$

This article outlines the impact of three key mental health disorders on parenting and young offspring, and describes implications for practice.

\section{Parenting with depression (including perinatal depression)}

Perinatal depression and anxiety (often co-occurring) are common mental health disorders affecting about $10 \%-$ $15 \%$ of women. They may begin antenatally, often relapse, and can have detrimental effects on infant and child development. ${ }^{7}$ The prevalence of these disorders in fathers is about half that of mothers. ${ }^{8}$ There is a moderate increase in the risk of paternal depression when the mother is depressed. ${ }^{9}$

\section{Parenting issues}

Parents with depression have more difficulties in interaction with their infants, compared with parents without depression. Depressed mothers interact differently with their infants - they tend to express fewer emotions and show more sad affect than non-depressed mothers. In addition, they are more intrusive, less involved, less responsive to infant signals, and show more covert as well as overt hostility such as anger, criticism and irritability toward their children. ${ }^{10}$

Parents' negative attributions mediate the positive relationship between their depressive symptoms and

\section{Nicholas M Kowalenko BM BS, FRANZCP. CertAdvTrngChild AdolescPsychiatry, Clinical Senior Lecturer, $^{1}$ and Chair $^{2}$ \\ Sarah P Mares BM BS, FRANZCP, CertChildPsychol, Consultant Infant. Child and Family Psychiatrist $^{3}$ \\ Louise K Newman MB BS(Hons), PhD, FRANZCP, Director ${ }^{4}$ \\ Anne E \\ Sved Williams MB BS, FRANZCP, DipPsychother, \\ Rosalind M Powrie BM BS, FRANZCP, AccredChildAdolesc Psychiatrist, Psychiatrist ${ }^{5}$ \\ Karin T M van Doesum PhD,
Researcher and Prevention Psychologist ${ }^{6}$}

1 Department of Psychological Medicine, University of Sydney and NSW Institute of Psychiatry, Sydney, NSW. 2 Faculty of Child and Adolescent Psychiatry.

Royal Australian and New Zealand College of Psychiatrists,
of Melbourne, VIC.

3 Alternate Care Clinic, Redbank House, Sydney, NSW. 4 Centre for Developmental Psychiatry and Psychology.

Monash University, Melbourne, VIC.

5 Perinatal and Infant Mental Health Services, Women's and Children's Hospital Child, Youth and Women's Health Network, Adelaide, SA. 6 Radboud

University Niimegen, Nijmegen, Netherlands,

nkowa@nsccahs. health.nsw.gov.au

doi: 10.5694/mjaoll.11285 frequency of physical punishment of their child. More frequent physical punishment, in turn, predicts increased child externalising behaviour. ${ }^{11}$ Punitive and harsh parenting practices greatly exacerbate the risk for problem behaviour in children who are assessed to be at genetic risk. $^{12}$

A parental history of childhood abuse increases the risk of parental depression, and these two factors are important determinants of parenting and infant temperament. ${ }^{13}$

\section{Children of parents with depression}

Although there are adverse effects of maternal depression on child attachment, ${ }^{9}$ mitigating factors have also been identified. ${ }^{14}$ Children of mothers who have been depressed shortly after birth show more behaviour problems in early childhood (particularly if the depression persists), lower IQ scores in late childhood, ${ }^{15}$ and elevated rates of affective disorders in adolescence when maternal depression recurs. ${ }^{16}$ Paternal depression during the postnatal period is independently associated with an increased risk of behaviour and socioemotional problems in Australian preschoolers. ${ }^{8}$ Psychopathology in fathers is a risk factor for toddlers' externalising behaviour problems when mothers have been previously depressed, and for toddlers' internalising problems when mothers have either a history of, or current, depressive symptoms. ${ }^{17}$

\section{Implications for practice}

It is generally assumed that the successful treatment of parental depression is associated with reduced psychopathology in offspring. This is evident for children aged 7-17 years. ${ }^{18}$ However, recent systematic reviews have found that the treatment of maternal postnatal depression may not be sufficient to improve cognitive development, attachment, temperament and other developmental markers in infants and toddlers ${ }^{19,20}$ without an explicit treatment focus on the mother-infant relationship. ${ }^{21}$ There is evidence for effectively treating mild to moderate maternal postnatal depression with non-directive counselling, cognitive behaviour therapy, interpersonal therapy and psychodynamic therapy, and more severe postnatal depression with psychotropics. ${ }^{22}$ However, these interventions, on their own, have not demonstrated sufficient benefit to infants and young children. Two treatments for maternal depression that may improve infant outcomes are described in Box 1. Identifying paternal mental health problems is an important first step towards appropriate interventions. ${ }^{28}$ 
1 Implications for practice: treatments for maternal depression to improve infant outcomes

A home-visiting intervention for depressed mothers and their infants

As part of a nationwide prevention program in the Netherlands for children of parents with mental illness, mothers and infants received 8-10 home visits from a prevention specialist. The intervention aimed to enhance the quality of the mother-child interaction by means of video feedback focusing on maternal sensitivity to the child's signals and needs. Cognitive restructuring of the mother's negative thinking, practical support, developmental education, baby massage and behaviour modelling were also included.

Improved mother-child interaction, attachment security and socioemotional functioning were found at 6 -month follow-up. ${ }^{23}$ At the age of 5 years, there were positive effects in children in the intervention group who experienced stressful life events. The data suggest that the early intervention might have served as a buffer against the development of externalising behaviour in reaction to stressful life events. ${ }^{24}$

With broad dissemination since the initial study, this intervention is offered in $70 \%$ of adult mental health centres in the Netherlands. One mother who participated in the study said: "I have learned to read my son Lukas and to enjoy to communicate with him. Before I thought he did not like me and I felt insecure about my parenting."

Preventing perinatal depression relapse - a mindfulness-based intervention

Mindfulness-based cognitive therapy (MBCT) is one of a number of mental health interventions incorporating mindfulness skills to specifically reduce relapse rates in recurrent major depression. ${ }^{25}$ A pilot study using MBCT modified for pregnant women ${ }^{26}$ showed favourable outcomes in reducing perinatal mood and anxiety symptoms with high acceptability. In addition, the practice of mindfulness, which is a way of intentionally directing attention to the present moment with acceptance and non-judgement, develops skills which may assist a parent to be more receptive, open and attuned to their infant and themselves. Mindfulness is closely related to an important capacity in early parenting and the capacity of a mother to reflect on her own and her child's internal mental experience. Impairment in this capacity is a risk factor for psychopathological conditions in offspring. Extending parents' mindfulness skills may promote improved relationships via increased emotional regulation and awareness, reduced parental stress, and greater acceptance and compassion for the parent and infant. ${ }^{27}$.

\section{Borderline personality disorder and parenting}

Borderline personality disorder (BPD) is a complex mental disorder characterised by difficulties in interpersonal functioning, mood instability and poor impulse control. Rapid shifts between idealisation and devaluation are common, reflecting a poor sense of identity. Relationships can be unstable and complicated. Individuals with BPD may also be anxious, depressed and unable to manage difficult feelings. Self-harm and substance misuse are common. ${ }^{29}$

The core features of BPD affect parenting capacity. The parent with BPD may have difficulties being emotionally available for their child and in managing feelings of frustration. Early parenting can be disrupted by the parent's difficulties in understanding their infant's emotional communication. ${ }^{30}$ Many individuals with BPD have histories of relationship disruption, trauma, abuse and neglect, and parenting can cause anxiety and bring back memories of the parent's own early trauma.

\section{Parenting issues}

Parenting presents several challenges for patients with BPD. Pregnancy may occur as a result of an impulsive sexual act or in an unstable abusive relationship. The desire to become a parent may be ambivalent, and the parent may have unrealistic expectations that a child will care for them. ${ }^{31}$ Parents with histories of abuse are at risk of repeating abuse and dysfunctional relationship patterns. ${ }^{32}$

Parenting risk for BPD is largely related to the parent's difficulties in forming a stable intimate relationship (attachment) with their own child.

\section{Children of parents with BPD}

Many infants of mothers with BPD have attachment disorganisation, disruptive behaviour disorders and features of attention deficit disorder. Lack of emotional availability in early parent-child relationships has a negative impact on the child's emerging understanding of emotions, empathy and relationships. ${ }^{33}$

\section{Implications for practice}

Assessment of parenting capacity in cases of severe BPD includes a review of the parent's feelings and ideas about the child and their ability to provide emotional care. The capacity of the parent to think about the child's emotional world (parental reflective capacity) ${ }^{34}$ is a key indicator of risk.

Assessment of the child should identify developmental delay (particularly in socioemotional domains), signs of anxiety, traumatic exposure, and relationship disturbance. Observational assessment of the parent and the child provides key information about the quality of the relationship and the child's emotional responses to the parent.

\section{Psychosis}

Psychotic conditions include schizophrenia, schizoaffective disorder, bipolar mood disorder and druginduced psychoses. Delusions, hallucinations and thought disorder may be chronic or intermittent, depending on the diagnosis. Symptoms of the illness and associated mood changes, lethargy, lack of motivation and compromised sleep may add to parenting disruption.

\section{Parenting issues}

For women with more severe psychotic illnesses (usually schizophrenia), pregnancy outcomes are compromised, with higher smoking rates, less antenatal care and higher rates of prematurity. ${ }^{35}$ Symptoms of the illness, social adversity and medication side effects can compromise parenting. There may be child protection authority involvement, with an increased likelihood of children being taken into care. ${ }^{5}$ 


\section{Managing psychosis: good practice points}

- Assess and provide team support with general practitioner from pregnancy onwards

- Assess and manage maternal mental state and parentinfant interaction

- Provide ongoing postnatal community support from a team with GP and mental health support, as well as childbased services, including maternal-child services, parenting services, and childcare with advocacy for these services

Offer sexual health and contraceptive advice

\section{Children of parents with psychosis}

Adverse impacts include compromised intellectual development with reduced IQ when risk factors such as mental illness, rigid attitudes to parenting, poverty, and low parental education are present. ${ }^{36}$ Other problem outcomes include infanticide, sudden infant death, compromised neurodevelopment, and attachment difficulties. $^{37}$

\section{Implications for practice}

Most authors cite a combination of good clinical practice - including accurate diagnosis and a biopsychosocial approach to management of the parental mental illness with attention to the infant, the parent-infant relationship, and the whole family (Box 2). Evidence for improving infant outcomes is scant. Appropriate care should begin in pregnancy, include consideration of the potential impact of psychotropic medications on parent and fetus, and is best supported by an expert team. ${ }^{38}$ Following birth, long-term community follow-up from a team including a general practitioner and specialised mental health and family workers is likely to provide benefit. ${ }^{39}$ Local networks may provide information on pathways to appropriate and specialised care such as specialist mother-baby units integrated with obstetric, perinatal and infant mental health care. ${ }^{40}$ Advocacy for mother and infant is generally required. ${ }^{41}$

\section{Conclusion}

Much current evidence suggests that the greatest impact of parental mental disorders occurs during the early stages of a child's life. ${ }^{42}$ Interventions targeting adverse influences on young children and their parents in the early years can improve child outcomes, ${ }^{43}$ and are cost-effective. ${ }^{44}$ Good practice in early interventions that support parents with mental illness and their young children ${ }^{45}$ offers opportunities to mitigate vulnerabilities and build strengths to optimise the development and wellbeing of the next generation, improve parental health, and enhance family functioning. Significant investment in intervention early in children's lives is required to achieve these aims in Australia. 46

Acknowledgements: This project is supported by the Children of Parents with a Mental Illness (COPMI) national initiative undertaken by the Australian Infant, Child, Adolescent and Family Mental Health Association with funding from the Australian Government Department of Health and Ageing. We thank Elizabeth Fudge, Project Manager of the COPMI initiative, for her assistance, and Jennifer Harris for her helpful comments. Competing interests: No relevant disclosures.

Provenance: Commissioned; externally peer reviewed.
1 Reupert AE, Maybery DJ, Kowalenko NM. Children whoes parents have a mental illness: prevalence, need and treatment. MJA Open 2012; 1 Suppl 1: 7-9.

2 Reupert A, Maybery D. Families affected by parental mental illness: a multiperspective account of issues and interventions. Am J Orthopsychiatry 2007; 77: 362-369.

3 Leschied AW, Chiodo D, Whitehead PC, Hurley D. The relationship between maternal depression and child outcomes in a child welfare sample: implications for treatment and policy. Child Fam Soc Work 2005; 10: 281-29l. doi: 10.1111/j.1365-2206.2005.00365.x.

4 Fudge E, Falkov A, Kowalenko N, Robinson P. Parenting is a mental health issue. Australas Psychiatry 2004; 12: 166-171.

5 Brockington I, Chandra P, Dubowitz $\mathrm{H}$, et al. WPA guidance on the protection and promotion of mental health in children of persons with severe mental disorders. World Psychiatry 2011; 10: 93-102.

6 National Research Council. Depression in parents, parenting, and children: opportunities to improve identification, treatment, and prevention. Washington, DC: The National Academies Press, 2009 http://www.nap.edu/catalog.php?record_id=12565 (accessed Mar 2012).

7 Buist A. Treatment of perinatal depression. Aust Prescr 2008; 31: 36-39. http://www.australianprescriber.com/magazine/31/2/36/9 (accessed Mar 2012).

8 Fletcher RJ, Feeman E, Garfield C, Vimpani G. The effects of early paternal depression on children's development. Med J Aust 2011; 195: 685-689.

9 Paulson JF, Bazemore SD. Prenatal and postpartum depression in fathers and its association with maternal depression: a meta-analysis. JAMA 2010; 303: 1961-1969.

10 Murray L, Cooper PJ, editors. Postpartum depression and child development. New York: The Guilford Press, 1997.

11 Callender KA, Olson SL, Choe DE, Sameroff AJ. The effects of parental depressive symptoms, appraisals, and physical punishment on later child externalizing behavior. J Abnorm Child Pyschol 2012; 40: 471-483.

12 Kim-Cohen J, Caspi A, Taylor A, et al. MAOA, maltreatment, and geneenvironment interaction predicting children's mental health: new evidence and a meta-analysis. Mol Psychiatry 2006; 11: 903-913.

13 Caldwell JG, Shaver PR, Li CS, Minzenberg MJ. Childhood maltreatment adult attachment, and depression as predictors of parental selfefficacy in at-risk mothers. J Aggression Maltreatment Trauma 2011; 20: 595-616. doi: 10.1080/10926771.2011.595763.

14 McMahon CA, Barnett B, Kowalenko NM, Tennant CC. Maternal attachment state of mind moderates the impact of postnatal depression on infant attachment. J Child Psychol Psychiatry 2006; 47: 660-669.

15 Hay DF, Pawlby S, Sharp D, et al. Intellectual problems shown by 11-year-old children whose mothers had postnatal depression. J Child Psychol Psychiatry 2001; 42: 871-889.

16 Halligan SL, Murray L, Martins C, Cooper PJ. Maternal depression and psychiatric outcomes in adolescent offspring: a 13-year longitudinal study. J Affect Disord 2007; 97: 145-154.

17 Dietz LJ, Jennings KD, Kelley SA, Marshal M. Maternal depression, parental psychopathology, and toddlers' behaviour problems. J Clin Child Adolesc Psychol 2009; 38: 48-61.

18 Pilowsky DJ, Wickramaratne P, Talati A, et al. Children of depressed mothers 1 year after the initiation of maternal treatment findings from the STAR*D-Child Study. Am J Psychiatry 2008; 165: 1136-1147.

19 Gunlicks ML, Weissman MM. Change in child psychopathology with improvement in parental depression: a systematic review. J Am Acad Child Adolesc Psychiatry 2008; 47: 379-389.

20 Poobalan AS, Aucott LS, Ross L, et al. Effects of treating postnatal depression on mother-infant interaction and child development: systematic review. Br J Psychiatry 2007; 191: 378-386.

21 Forman DR, O'Hara MW, Stuart S, et al. Effective treatment for postpartum depression is not sufficient to improve the developing mother-child relationship. Dev Psychopathol 2007; 19: 585-602.

22 Austin MP, Highet N; Guidelines Expert Advisory Committee. Clinical practice guidelines for depression and related disorders - anxiety, bipolar disorder and puerperal psychosis - in the perinatal period. A guideline for primary care professionals. Melbourne: beyondblue: the national depression initiative, 2011. http://www.beyondblue.org.au/ index.aspx?link_id=6.1246 (accessed Mar 2012).

23 van Doesum KT, Riksen-Walraven JM, Hosman CMH, Hoefnagels C. A randomized controlled trial of a home-visiting intervention aimed at preventing relationship problems in depressed mothers and their infants. Child Dev 2008; 79: 547-56].

24 Kersten-Alvarez LE, Hosman CM, Riksen-Walraven JM, et al. Long-term effects of a home-visiting intervention for depressed mothers and their infants. J Child Psychol Psychiatry 2010; 51: 1160-1170.

25 Segal ZV, Williams JMG, Teasdale JD. Mindfulness-based cognitive therapy for depression: a new approach to preventing relapse. New York: The Guilford Press, 2002.

26 Vieten C, Astin J. Effects of a mindfulness-based intervention during pregnancy on prenatal stress and mood: results of a pilot study. Arch Womens Ment Health 2008; 11: 67-74. 
27 Duncan LG, Coatsworth JD, Greenberg MT. A model of mindful parenting: implications for parent-child relationships and prevention research. Clin Child Fam Psychol Rev 2009; 12: 255-270.

28 Fletcher RJ, Maharaj ON, Fletcher Watson $\mathrm{CH}$, et al. Fathers with a mental illness: implications for clinicians and health services. MJA Open 2012; 1 Suppl 1: 34-36.

29 Eaton NR, Krueger RF, Keyes KM, et al. Borderline personality disorder co-morbidity: relationship to the internalizing-externalizing structure of common mental disorders. Psychol Med 2011; 4l: 104l-1050.

30 Newman L, Stevenson C. Parenting and borderline personality disorder: ghosts in the nursery. Clin Child Psychol Psychiatry 2005; 10: 385-394. doi: 10.1177/1359104505053756.

31 Newman LK, Stevenson CS, Bergman LR, Boyce P. Borderline personality disorder, mother-infant interactions and parenting perceptions: preliminary findings. Aust N Z J Psychiatry 2007; 4l: 598-605.

32 Solomon J, George C. Intergenerational transmission of dysregulated maternal caregiving: mothers describe their upbringing and childrearing. In: Mayseless O, editor. Parenting representations: theory, research, and clinical implications. New York: Cambridge University Press, 2006: 265-295.

33 Fonagy P, Target M, Gergley G. Attachment and borderline personality disorder. A theory and some evidence. Psychiatr Clin North Am 2000; 23 : 103-122.

34 Slade A. Parental reflective functioning: an introduction. Attach Hum Dev 2005; 7: 269-281.

35 Matevosyan NR. Pregnancy and postpartum specifics in women with schizophrenia: a meta-study. Arch Gynecol Obstet 2011; 283: 141-147.

36 Sameroff AJ. Environmental risk factors in infancy. Pediatrics 1998; 102 (5 Suppl E): 1287-1292.

37 Sved Williams A. Infants of mothers with mental illness. In: Cowling V editor. Children of parents with mental illness 2: personal and clinical perspectives. Melbourne: ACER Press, 2004: 17-40.
38 Nguyen TH, Faulkner D, Frayne JS, et al. Obstetric and neonatal outcomes of pregnant women with severe mental illness at a specialist antenatal clinic. MJA Open 2012; 1 Suppl 1: 26-29.

39 Nicholson J, Albert K, Gershenson B, et al. Family options for parents with mental illnesses: a developmental, mixed methods pilot study. Psychiatr Rehabil J 2009: 33: 106-114.

40 Sved Williams A, Cowling C, editors. Infants of parents with mental illness: developmental, clinical, cultural and personal perspectives. Bowen Hills, Qld: Australian Academic Press, 2008.

41 Lagan M, Knights K, Barton J, Boyce PM. Advocacy for mothers with psychiatric illness: a clinical perspective. Int J Ment Health Nurs 2009; 18: 53-61.

42 Hosman CMH, van Doesum KTM, van Santvoort F. Prevention of emotional problems and psychiatric risks in children of parents with a mental illness in the Netherlands: I. The scientific basis to a comprehensive approach. Adv Ment Health 2009; 8: 250-263.

43 Royal Australian and New Zealand College of Psychiatrists. Report from the Faculty of Child and Adolescent Psychiatry. Prevention and early intervention of mental illness in infants, children and adolescents: planning strategies for Australia and New Zealand, 2010. Melbourne: RANZCP, 2010. http://www.ranzcp.org/images/stories/ ranzcp-attachments/Resources/peips_report.pdf (accessed Mar 2012)

44 Royal Australian and New Zealand College of Psychiatrists. Report from the Faculty of Child and Adolescent Psychiatry. The cost effectiveness of prevention and early intervention of mental illness in infants, children and adolescents, September 201l. Melbourne: RANZCP, 201l. http://www.ranzcp.org/images/stories/ranzcpattachments/Resources/Submissions/peips_cost_effectiveness_ final_20110803.pdf (accessed Mar 2012).

45 Beardslee WR, Ayoub C, Avery MW, et al. Family Connections: an approach for strengthening early care systems in facing depression and adversity. Am J Orthopsychiatry 2010; 80: 482-495.

46 Kowalenko N. Children aged $0-5$ with a parent who has a mental illness: the need for early intervention. Adv Ment Health 2009; 8: 215-221. 